\title{
Pirinanın farklı nem içeriklerinde peletlenmesi işleminin peletlerin fiziksel özellikleri üzerine etkileri
}

\section{The effects of pelletizing moisture on pellet physical properties of olive cake pellets}

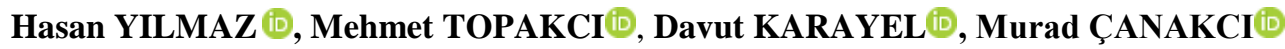 \\ Akdeniz Üniversitesi, Ziraat Fakültesi, Tarım Makinaları ve Teknolojileri Mühendisliği Bölümü, Konyaaltı, Antalya, Türkiye \\ Sorumlu yazar (Corresponding author): H. Y1lmaz, e-posta (e-mail): hasanyilmaz@akdeniz.edu.tr \\ Yazar(lar) e-posta (Author e-mail): mtopakci@akdeniz.edu.tr, dkarayel@ akdeniz.edu.tr, mcanakci@ akdeniz.edu.tr
}

\section{MAKALE BİLGİSİ}

Alınış tarihi 28 Aralık 2020

Düzeltilme tarihi 12 Şubat 2021

Kabul tarihi 16 Şubat 2021

\section{Anahtar Kelimeler:}

Zeytin

Pirina

Pelet

Biyokütle

Pelet fiziksel özellikleri

\section{ÖZ}

Bu çalışmada, zeytinyağı üretimi sırasında yan ürün olarak ortaya çıkan pirina üç farklı nem içeriğinde $(\% 14, \% 17$ ve \%20) peletlenmiș ve farklı nem içeriklerinin peletlerin fiziksel kalite değerleri üzerine etkisi araştırılmıştır. Nem içeriği değişkenine bağlı olarak pelet üretim koşulları ile ilgili üretim kapasitesi ve özgül enerji tüketimi değerleri belirlenmiştir. Pelet fiziksel özellikleriyle ilgili nem içeriği, parça yoğunluğu, yığın yoğunluğu, dayanıklılık direnci ve sıkıştırma direnci testleri yapılmıştır. Çalışma sonunda en yüksek üretim kapasitesi ve en düşük özgül enerji tüketimi sırasıyla $225.59 \mathrm{~kg} \mathrm{~h}^{-1}$ ve $45.13 \mathrm{kWh}^{-1}$ ton $\% 20$ nem içeriğine sahip pirinada elde edilmiştir. Yüksek nem içeriğinde pelet üretiminin daha kolay gerçekleştiği ve daha az enerji gerektirdiği belirlenmiştir. Peletleme işleminde nem düzeyi artışının, parça yoğunluğu ve yığın yoğunluğu değişimine etkisi istatistiksel açıdan önemsiz bulunmuştur. Pelet dayanıklılık direnci peletleme neminin artmasıyla artış göstermiş, en yüksek dayanıklılık direnci $\% 20$ nem içeriğindeki peletleme ișleminde $\% 70$ olarak hesaplanmıștır. Elde edilen peletlerin nem içeriği, yığın yoğunluğu ve dayanıklılık direnci değerleri EnPlus pelet standartlarını karşılamamaktadır. Her üç nem içeriğinde üretilen peletlerin dayanıklı yapıda olmadığı saptanmıştır. Pirina içerisinde bulunan zeytin çekirdeği parçalarının, pirinanın pelet formasyonu kazanması ve dayanıklı yapıda kalmasını engellediği sonucuna varılmıştır.

\section{ARTICLE INFO}

Received 28 December 2020

Received in revised form 12 February 2021

Accepted 16 February 2021

\section{Keywords:}

Olive

Olive Cake

Pomace

Biomass

Pellet physical properties

\begin{abstract}
In the study, olive cake, which was obtained during olive oil production, was pelleted at three different moisture contents $(14 \%, 17 \%$ and $20 \%)$. Depending on the moisture content variable, the production capacity and specific energy consumption values related to the pellet production conditions were determined. Moisture content, particle density, bulk density, specific compression resistance and pellet durability index tests were carried out regarding the pellet physical properties. At the end of the study, the highest production capacity and the lowest specific energy consumption were obtained for the raw material with $20 \%$ moisture content with $225.59 \mathrm{~kg} \mathrm{~h}^{-1}$ and $45.13 \mathrm{kWh} \mathrm{ton}^{-1}$, respectively. It has been observed that pellet production with high moisture content is easier and requires less energy. The effect of the increase of pelletizing moisture on the change of particle density and bulk density was found to be statistically insignificant $(\mathrm{p}<0.05)$. Pellet durability increased with the increase of pelleting moisture, and the highest pellet durability index was calculated as $70 \%$ in the pelleting process at $20 \%$ moisture content. The moisture content, bulk density and pellet durability index values of the pellets obtained do not meet the EnPlus pellet standards. It has been observed that the pellets produced in all three moisture content are quite unstable and weak form. It was concluded that the olive seed pieces in the olive cake prevent the gaining pellet formation and having durable structure.
\end{abstract}




\section{Giriş}

Biyokütle peletleri son yıllarda alternatif katı yakıt kullanımına yeni bir yaklaşım getirmiştir. Dünyada biyokütle pelet üretiminde hammadde olarak yaygın bir şekilde orman endüstrisi yan ürünleri veya artıkları kullanılmaktadır. $\mathrm{Bu}$ nedenle biyokütle peletleri genel anlamda "odun peleti" olarak adlandırılır. Üretim teknolojisinin kolay ve erişilebilir olması, hammadde tedarik zincirinin varlığı ve bilinen yakıt özellikleri, odun peleti üretimini ve kullanımını arttırmıştır. 2018 yılı sonunda dünya genelinde pelet üretimi 2017 yılına göre \%14 artarak 55 milyon ton seviyesine ulaşmıştır. Dünya pelet üretiminde \%36 ile en büyük paya sahip olan Çin'i \%30 ile AB ülkeleri, \%20 ile Kuzey Amerika ülkeleri ve \%14 ile diğer ülkeler takip etmektedir (Calderón ve ark. 2019). Pelet sektöründeki hızlı büyüme, hammadde fiyatlarındaki rekabeti artırmış ve tedarikini zorlaştırmıştır. Bu nedenle orman ürünleri artıklarına ek olarak alternatif hammadde kullanımı, hammadde sorununa çevre dostu bir yaklaşım olarak görülmektedir (Mostafa ve ark. 2019).

Pelet sektöründeki hammadde açığının kapatılması ve mevcut biyokütle artıklarının değerlendirilmesi açısından tarımsal artıklar önemli bir potansiyele sahiptir. Farklı tarımsal üretim işlemleri sonucunda hasat işlemleri sonrası, meyve bahçelerinde budama işlemleri sonrası ve ürün işleme sonrası ortaya çıkan artıklar pelet üretiminde hammadde olarak değerlendirilebilir özellikteki biyokütle kaynaklarındandır.

Pirina, tarımsal artıklardan ürün işleme artıkları kapsamına girmektedir ve zeytinyağ 1 üretimi sırasında ezilerek işlemden geçen zeytinlerden arta kalan çekirdek, posa ve kabuktan oluşmaktadır. Zeytinyağı üretimi sonrasında yan ürünlerden biri olan pirina gıda, endüstri ve enerji sektörlerinde hammadde olarak kullanılabilmektedir (Yıldırım ve Tunalığlu 2016). Ülkemizde zeytin üretimi, 2019 y1lında 0.4 Mton sofralık, 1.1 Mton yağlık olmak üzere toplam 1.5 Mton düzeyindedir (TÜİK 2020). Yağlık zeytinin işlenmesi sonucu zeytin miktarının yaklaşık \%64.3'ü pirina olarak ortaya çıkmaktadır (Hocaoglu ve ark. 2017). Bu değerler dikkate alındığında, 2019 yılında ülkemizde zeytinyağı üretiminden ortaya çıkan toplam pirina miktarının yaklaşık 0.7 Mton olduğu hesaplanmaktadır. Ülkemizde zeytin yetiştiriciliğinin yapıldığ 1 bölgelerde pirinanın katı yakıt olarak kullanımı yaygındır. Pirinalar, işletme koşulları ve yakma sistemi özelliklerine göre doğrudan yakılmakta, pelet veya briket olarak kullanılmaktadır (Al-Widyan ve ark. 2002; Korkut ve ark. 2016).

Pirina peleti üretimindeki mevcut uygulamalar, işletme koşulları ve kapasitesine göre değişkenlik göstermekte olup genellikle pirina elde edildikten sonra yığın halinde depolanarak pelet üretimine hazırlanmaktadır. Kurutma işlemi için depolama yöntemi veya kurutucu sistemler kullanılmaktadır. Arından peletleme sistemlerindeki sicak buhar ve nemlendirme ünitelerinin kontrolüyle pelet çıkışı anlık olarak gözlemlenerek katı pelet formu elde edilmektedir.

Yapılan araştırmalarda, yaygın kullanılmalarına rağmen literatürde pirina peleti üretim koşullarının incelendiği ve pelet fiziksel özelliklerinin belirlendiği bir çalışmaya rastlanılmamıştır.

Tarımsal artıkların farklı karakteristiklere sahip olmalarının genel anlamda artıkların pelet olarak kullanımını sınırlandırdığ söylenebilir. Bu nedenle araştırmacılar çeşitli tarımsal artıkları değişken koşullarda peletleyerek pelet üretim koşulları ile pelet özelliklerini ortaya koymuşlardır. Bu çalışmalar ile tarımsal artıklardan üretilen peletlerin ilgili standartlara uygunluğu ve yakıt özellikleri konusunda bir veri tabanı oluşmaktadır.

Peletleme işlemini ve pelet özelliklerini etkileyen başlica faktörler hammaddenin parçacık boyut dağılımı (Kirsten ve ark. 2016), peletleme nemi (Serrano ve ark. 2011; Garcia-Maraver 2015), yapıştırıcı kullanımı (Arzola ve ark. 2012) ve hammadde karışım oranı (Filbakk ve ark. 2011)'dır. Farklı tarımsal artıklarla yapılan çalışmalarda, fiziksel olarak dayanıklı peletlerin üretilebilmesi için peletleme nem içeriğinin \%8-20 aralığında değişkenlik gösterebildiği bildirilmiş̧ir (Jiang ve ark. 2016; Talero Rojas ve ark. 2016; Huang ve ark. 2017; Zvicevičius ve ark. 2018; González ve ark. 2020). Peletlerin fiziksel olarak dayanıklı yapıda olmaları, yakma sistemlerinde verimli yakılabilmesi, taşıma ve depolama işlemlerinin etkin bir biçimde yürütülebilmesi açısından önemlidir (Akdeniz ve Shishvan 2015; Agar ve ark. 2018). Artık çeşidi ve üretim koşulları değişkenlerinin pelet kalitesini ve üretim verimliliğini etkilemesi, her bir biyokütle kaynağının değişken koşullarda peletlenerek fiziksel özelliklerinin belirlenmesi gerekliliğini doğurmaktadır.

$\mathrm{Bu}$ araştırmada, bir zeytinyağı fabrikasından öğütülmüş formda alınan pirina farklı nem içeriklerinde peletlenerek, üç farklı nem içeriğinde pirinanın peletleme koşulları ve pelet fiziksel özelliklerinin belirlenmesi amaçlanmıştır.

\section{Materyal ve Yöntem}

Denemeler Akdeniz Üniversitesi Ziraat Fakültesi Tarım Makinaları ve Teknolojileri Bölümü Atölyesinde ve laboratuvarlarında gerçekleştirilmiştir.

Çalışmadaki pelet hammaddesi olan pirina, Antalya ilinde faaliyet gösteren orta ölçekli bir zeytinyağı fabrikasından $5 \mathrm{~mm}$ elek delik çapında ögütülmüş olarak temin edilmiştir.

Peletleme işleminden önce pirina güneş 1 şığ 1 altında beton zeminde 2 gün bekletilerek doğal şartlarda kurutulmuştur. Kurutma işlemi sonrasında \%11.92 olan nem içeriğinde ön denemeler gerçekleştirilmiş olup, pelet formunun sağlanabileceği nem içeriğinin minimum \%13-14 nem içeriği aralığ kontrollü olarak \%13-14, \%17-18 ve \%20-21 düzeylerinde nemlendirilerek üç farklı materyal grubu hazırlanmıştır. Nemlendirme işleminde, eklenecek su miktarının belirlenmesi için aşağıdaki eşitlik kullanılmıştır (Coşkun et al. 2006) .

$$
Q=W_{i}\left(M_{f}-M_{i}\right) /\left(100-M_{f}\right)
$$

Eşitlikte, $Q$ : Eklenecek su miktarı $(\mathrm{g}) ; W_{i}$ : Materyalin ilk ağırlığı $(\mathrm{g}) ; M_{i}$ : Materyalin ilk nem içeriği $(\%) ; M_{f}$ : Materyalin istenen nem içeriği (\%). Nemlendirme sırasında, materyal karıştırıcının içine dökülmüştür. Eşitlik ile belirlenen su miktarı materyale püskürtülerek karıştırıcı 10 dakika boyunca çalıştırılmıştır. Nemlendirilen materyal ağzı kapalı plastik torbalarda 2 gün süreyle bekletilerek nemin homojen olarak yayılması sağlanmıştır.

Pirinanın parçacık boyut dağılımının belirlenmesinde 200 $\mathrm{mm}$ çapında, $50 \mathrm{~mm}$ derinliğinde ve $0.125,0.25,0.5,1,1.7$, 2.36 ve $3 \mathrm{~mm}$ delik çaplarında 7 adet elekten oluşan elek analiz seti kullanılmıştır. Elek analizi verileri sonuçlarına göre geometrik ortalama çap değerinin hesaplanmasında verilen eşitlik kullanılmıştır (ASAE S319.3 2003). 


$$
d_{\mathrm{gw}}=\log ^{-1}\left[\sum_{\mathrm{i}=1}^{\mathrm{n}}\left(\mathrm{w}_{\mathrm{i}} \log (\mathrm{di})\right) / \sum_{\mathrm{i}=1}^{\mathrm{n}} \mathrm{w}_{\mathrm{i}}\right]
$$

Eşitlikte, $d_{g w}$ : Geometrik ortalama çap $(\mathrm{mm}) ; w_{i}$ : Elekte biriken materyal kütlesi $(\mathrm{g}) ; d i$ : Elek açıklığı $(\mathrm{mm}) ; n$ : Elek sayısı'nı ifade etmektedir. Çalışmada kullanılan pirinanın parçacık boyut dağılımı Şekil 1'de yer almaktadır.

Pirina hammaddesinin parçacık boyut dağılımı incelendiğinde toplam materyalin yaklaşık \%80'inin $1 \mathrm{~mm}$ ve büyük parçacıklardan oluştuğu görülmektedir.

Pirinanın hammadde fiziksel özelikleri ve nemlendirme işlemi sonrası materyal nem içerikleri Çizelge 1'de yer almaktadır.

Peletleme işleminde, peletleme ünitesi motor gücü $7.5 \mathrm{~kW}$ olan düz kalıplı otomatik beslemeli bir peletleme sistemi kullanılmıştır. Peletleme sisteminin şematik görünümü ve pelet kalıbı ölçüleri Şekil 2'de yer almaktadır.

Peletleme işlemleri sırasında pelet üretim kapasitesi $60 \mathrm{~s}$ boyunca üretilen peletlerin tartılmasiyla $\mathrm{kg} \mathrm{h}^{-1}$ olarak hesaplanmıştır. Peletleme sisteminin enerji tüketimi değerlerinin ölçülmesinde Chauvin Arnoux CA 8332B 3 fazlı portatif enerji analizörü kullanılmıştır. Peletleme işlemi sırasında hammadde, pelet kalıbı ve peletleme silindirleri arasında oluşan sürtünmeden kaynaklanan pelet kalıbı sıcaklığı Testo 110 sıcaklık ölçüm cihazı ve yüzey sıcaklığı ölçüm probuyla ölçülmüştür.

Peletlerin fiziksel kalitelerini belirlemek amaciyla nem içeriği, parça yoğunluğu, yığın yoğunluğu, dayanıklılık direnci ve sıkıştırma direnci testleri gerçekleştirilmiştir. Peletlerin ve hammaddenin nem içeriği $105^{\circ} \mathrm{C}^{\prime}$ de $24 \mathrm{~h}$ bekletilmesiyle yaş bazda hesaplanmıştır (ASTM 2019).

Çizelge 1. Pirinanın hammadde fiziksel özellikleri.

Table 1. Raw material physical properties of olive cake.

\begin{tabular}{cccc}
\hline Materyal & $\begin{array}{c}\text { Yoğunluk } \\
\left(\mathrm{kg} \mathrm{m}^{-3}\right)\end{array}$ & $\begin{array}{c}\text { Geometrik } \\
\text { ortalama çap } \\
(\mathrm{mm})\end{array}$ & $\begin{array}{c}\text { Nemlendirme sonras1 } \\
\text { nem içeriği (\%) }\end{array}$ \\
\hline \multirow{2}{*}{ Pirina } & 574.61 & 2.012 & $\frac{14.24( \pm 0.10)^{*}}{n}$ \\
\cline { 3 - 3 } & & & $17.68( \pm 0.07)$ \\
\hline
\end{tabular}

*Parantez içindeki değerleri ortalamaların standart hatasını ifade etmektedir.

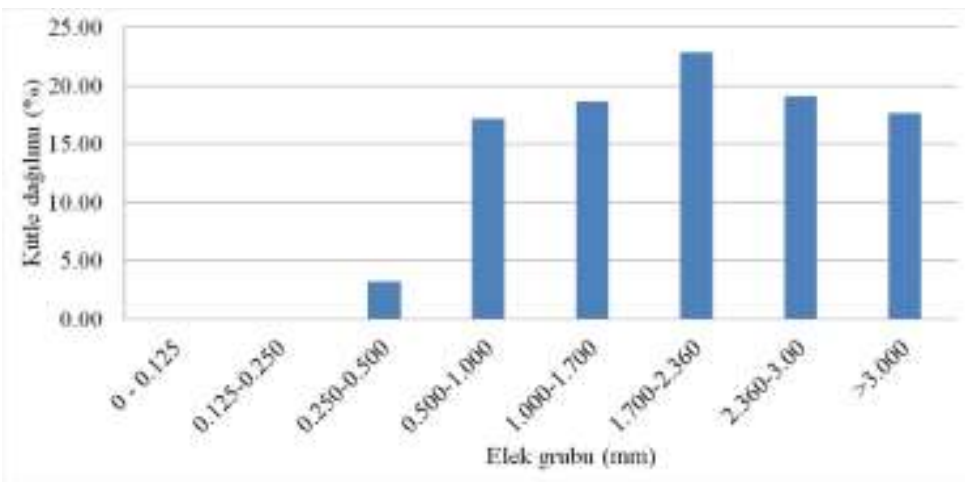

Şekil 1. $5 \mathrm{~mm}$ elek delik çapında öğütülmüş pirinanın parçacık boyut dağılımı.

Figure 1. Particle size distribution of ground olive cake with a $5 \mathrm{~mm}$ sieve hole diameter.

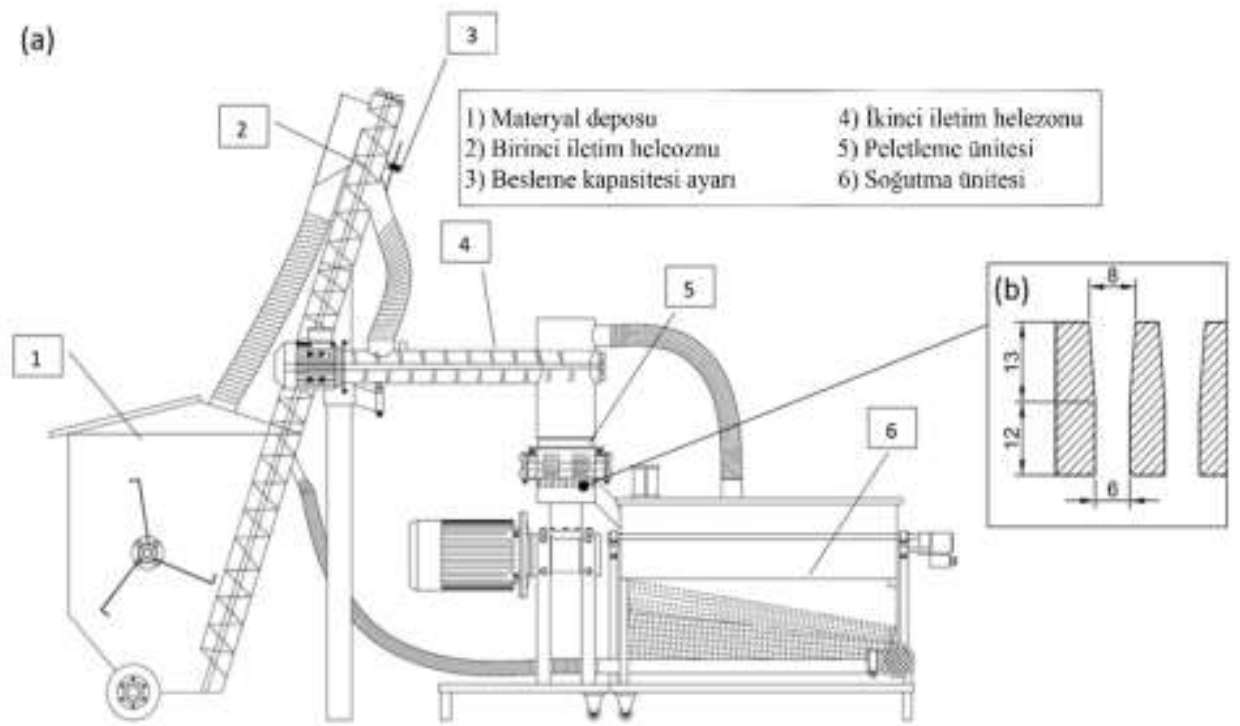

Şekil 2. Denemelerde kullanılan peletleme sistemi (a) ve pelet kalıbı (b).

Figure 2. Pelletizing system (a) and pellet die (b) used in the experiments. 
Pelet parça yoğunluğu değerleri her bir gruptaki yaklaşık $100 \mathrm{~g}$ peletin çap, boy ve kütle değerlerinin ölçülmesiyle $\mathrm{kg} \mathrm{m}^{-3}$ olarak hesaplanmıştır (ASAE 2001).

Hammadde ve peletlerin yığın yoğunluğu değerleri EN 15103 (2009) standardına göre imal edilen 5 litre hacmindeki yığın yoğunluğu belirleme kabıyla gerçekleştirilmiştir.

Peletlerin dayanıklilik direnci EN 15210-1 (2009) standardına göre yapılmıştır. $\mathrm{Bu}$ testte $500 \mathrm{~g}$ pelet örneği 10 dakika boyunca döndürülmeye maruz bırakılarak test öncesi ve test sonrası kütle kaybına göre \% olarak hesaplanmıştır.

Sıkıştırma direnci testinde maksimum yük kapasitesi 60 ton olan hidrolik basınç test cihazı kullanılmıştır. Bu teste boy ve çap değerleri ölçülmüş peletler iki plaka arasına yatay olarak yerleştirilerek sabit hızla yük uygulanmıştır. Peletler kırılana kadar uygulanan yük plaka altında bulunan yük hücresinden bilgisayara kaydedilerek maksimum kırılma kuvveti $\mathrm{N}$ ve gerilme direnci Mpa olarak hesaplanmıştır.

Yapılan testler üç tekerrürlü olarak gerçekleştirilmiş ve sonuçların istatistiksel açıdan değerlendirilmesinde SPSS programı kullanılmış olup varyans analizi ve Duncan çoklu karşılaştırma testi uygulanmıştır.

\section{Bulgular ve Tartışma}

Üç farklı peletleme neminde \%13-14 (PN1), \%17-18 (PN2) ve \%20-21 (PN3) olmak üzere üretilen pirina peletlerinde pirina içeriğindeki zeytin çekirdeği parçaları peletlerin fiziksel görünümlerine kıyaslanabilir düzeyde etki etmiştir. Peletlemeden önce pirina hammaddesi ve üç farklı peletleme neminde üretilen pirina peletleri Şekil 3'de yer almaktadır.

Peletleme neminin artışının hammaddenin bağlayıcılık faktörünü arttırarak iri parçalı zeytin çekirdeklerinin pelet içerisine nüfuz etmesini kolaylaştırdığı söylenebilir.

Pirinanın öğütme işlemi sırasında $5 \mathrm{~mm}$ delik çapında elek kullanılmıştır. $\mathrm{Bu}$ nedenle pirina içerisinde yer alan zeytin çekirdekleri yă ve nemin de etkisiyle toz formuna getirilemeden elekten geçerek materyal içerisinde sert ve iri parçacıklı zeytin çekirdeklerinin oluşmasına neden olmuştur. Yapılan çalışmalarda 4-5 mm elek delik çapında ögütülen bitkisel materyalleri geometrik ortalama çap değerleri, materyalin lifli, odunsu, otsu yapısına bağlı olarak 0.44-1.02 $\mathrm{mm}$ aralığında elde edilmiştir (Bilgin ve ark. 2014; Bilgin ve ark. 2015a, 2015b; Y1lmaz ve ark. 2020). Pirinanın geometrik ortalama çap değeri $2.012 \mathrm{~mm}$ ile belirtilen değerlerin üzerindedir.

Artan nem içeriklerinde yapılan peletleme işleminde pelet üretim kapasitesi ve özgül enerji tüketimi değişimleri Şekil 4'de yer almaktadır.

Peletleme nemindeki artış pirinanın sıkışarak pelet formu kazanmasını kolaylaștırmış ve pelet kalıbı deliklerinde akışkanlığı arttırarak birim zamanda daha fazla pelet üretimine neden olmuştur. Nem içeriğinin artışı materyalin kalıp deliklerinde şekil almasını ve pelet formunda ilerlemesini kolaylaştırdığı için materyal/kalıp/silindirler arası sürtünmeyi azaltarak pelet kalıbı sıcaklığı ve özgül enerji tüketimini düşürmüştür. En yüksek üretim kapasitesi ve en düşük özgül enerji tüketimi PN3 peletlerinde sirasiyla $225.59 \mathrm{~kg} \mathrm{~h}^{-1}$ ve 45.13 $\mathrm{kWh}$ ton $^{-1}$ olarak hesaplanmıştır.

Artan peletleme nemlerinde elde edilen pirina peletlerinin fiziksel özellikleri Çizelge 2'de yer almaktadır.

Biyokütlenin yakılması sırasında 1sı enerjisi ilk olarak nemin buharlaşmasında harcanır (Cheng ve ark. 2018). Bu nedenle pelet neminin mümkün olduğunca düşük değerde olmas1 beklenir. ENplus (2015) tarafindan peletlerin etkin kullanımı için nem içeriklerinin $\leq \% 10$ olması gerektiği bildirilmiştir. Çalışmada üretilen peletlerin nem içerikleri $\% 10.95-\% 17.08$ değerleri arasındadır. Belirtilen değerler ENPlus (2015) standardının gerekliliğini karşılamamaktadır. Peletleme sırasında pelet kalıbının sicaklığına maruz kalan materyal \%3-4 oranında nem kaybederek peletlerin neminin düşmesine sebep olmuştur.

Üretilen peletlerin parça yoğunluğu, yığın yoğunluğu ve dayanıklılık direnci değerlerinin nem içeriğine göre değișimi Şekil 5 'te yer almaktadır.

Parça yoğunluğu ve yığın yoğunluğu peletlerin depolama ve nakliye işlemelerinin etkin bir şekilde yapılması açısından önem arz etmektedir (Carroll ve Finnan 2012). Çizelge 2'de görüldüğü gibi pirina peletlerinde nem içeriğinin parça yoğunluğu ve yığın yoğunluğu üzerine etkisi istatistiksel açıdan önemsiz bulunmuştur $(\mathrm{p}<0.05)$. Yapılan Duncan çoklu karşılaştırma testi sonuçlarına göre ise PN1 peletlerinin yığın yoğunluğunun $\mathrm{PN} 3$ peletlerinden yüksek olduğu, PN2 peletleri ile PN1 ve PN3 peletleri arasındaki farklılığın önemsiz olduğu saptanmıştır. Artan nem içeriği materyalin yapıştırıcı özelliği arttırarak peletlere daha yoğun bir yapı kazandırmış olup hammaddeye oranlar 1.5-1.6 kat yoğun peletler üretilmiştir.
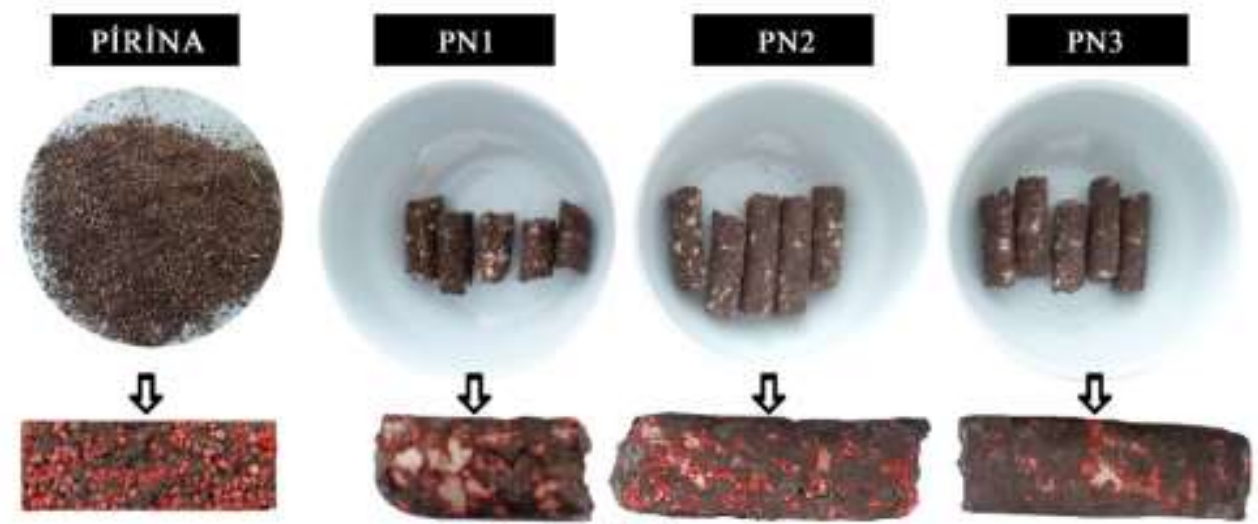

$\square$ Zeytin çekirdeği parçalan

Şekil 3. Üç farklı nem içeriğinde üretilen pirina peletleri.

Figure 3. Olive cake pellets produced at three different moisture contents. 


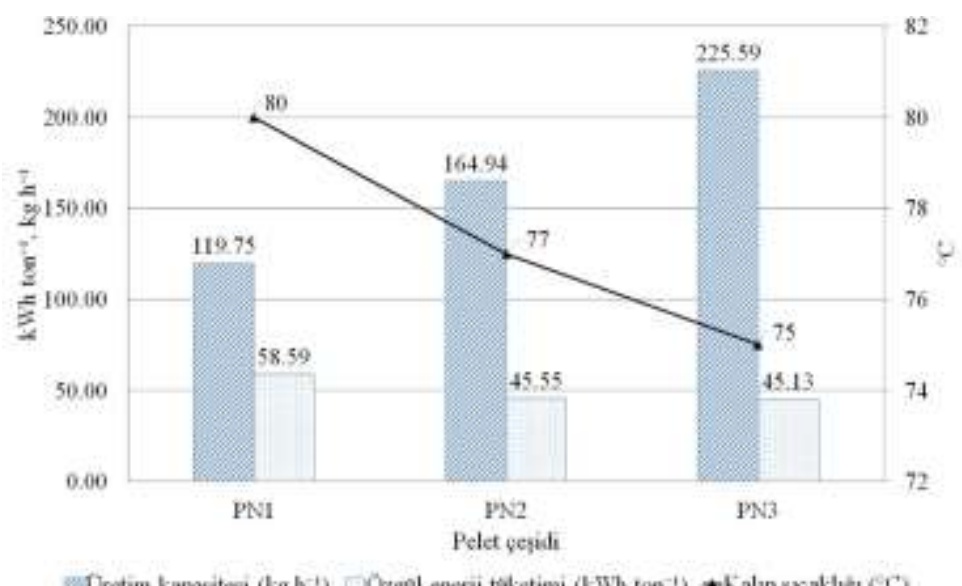

Şekil 4. Farklı nem içeriğinde üretilen peletlerin üretim kapasitesi, özgül enerji tüketimi ve kalıp sıcaklığı değişimleri.

Figure 4. Production capacity, specific energy consumption and die temperature changes of olive cake pellets produced at different moisture contents.

Çizelge 2. Farklı nem içeriğinde üretilen pirina peletlerinin fiziksel özellikleri.

Table 2. Physical properties of olive cake pellets produced at different moisture contents.

\begin{tabular}{|c|c|c|c|c|c|c|c|c|}
\hline \multirow{2}{*}{ Pelet } & \multirow{2}{*}{$\begin{array}{l}\text { MC } \\
(\%)\end{array}$} & \multirow{2}{*}{$\begin{array}{c}\mathbf{L} \\
(\mathbf{m m})\end{array}$} & \multirow{2}{*}{$\begin{array}{c}\text { D } \\
(\mathbf{m m})\end{array}$} & \multirow{2}{*}{$\begin{array}{c}\text { PD } \\
\left(\mathrm{kg} \mathrm{m}^{-3}\right)\end{array}$} & \multirow{2}{*}{$\begin{array}{c}\text { BD } \\
\left(\mathrm{kg} \mathrm{m}^{-3}\right)\end{array}$} & \multirow{2}{*}{$\begin{array}{l}\text { PDI } \\
(\%)\end{array}$} & \multicolumn{2}{|c|}{ CR } \\
\hline & & & & & & & (N) & (Mpa) \\
\hline PN1 & $\begin{array}{c}10.95^{\mathrm{a}} \\
( \pm 0.02)^{*}\end{array}$ & $\begin{array}{c}14.43^{\mathrm{a}} \\
( \pm 1.09) \\
\end{array}$ & $\begin{array}{c}6.55^{\mathrm{a}} \\
( \pm 0.01) \\
\end{array}$ & $\begin{array}{c}907.82^{\mathrm{a}} \\
( \pm 10.64)\end{array}$ & $\begin{array}{l}554.24^{\mathrm{b}} \\
( \pm 1.45) \\
\end{array}$ & $\begin{array}{c}60.63^{\mathrm{a}} \\
( \pm 1.12) \\
\end{array}$ & $\begin{array}{c}50.58^{a} \\
( \pm 1.12) \\
\end{array}$ & $\begin{array}{c}0.25^{\mathrm{a}} \\
( \pm 0.01) \\
\end{array}$ \\
\hline PN2 & $\begin{array}{c}13.62^{\mathrm{b}} \\
( \pm 0.04)\end{array}$ & $\begin{array}{l}18.17^{\mathrm{ab}} \\
( \pm 1.81)\end{array}$ & $\begin{array}{c}6.57^{\mathrm{a}} \\
( \pm 0.01)\end{array}$ & $\begin{array}{c}929.06^{\mathrm{a}} \\
( \pm 14.74)\end{array}$ & $\begin{array}{c}540.31^{\mathrm{ab}} \\
( \pm 5.68)\end{array}$ & $\begin{array}{c}64.83^{b} \\
( \pm 0.11)\end{array}$ & $\begin{array}{c}68.15^{\mathrm{a}} \\
( \pm 0.11)\end{array}$ & $\begin{array}{c}0.35^{\mathrm{b}} \\
( \pm 0.02)\end{array}$ \\
\hline PN3 & $\begin{array}{c}17.08^{c} \\
( \pm 0.02) \\
\end{array}$ & $\begin{array}{c}19.55^{\mathrm{b}} \\
( \pm 0.85) \\
\end{array}$ & $\begin{array}{c}6.60^{\mathrm{a}} \\
( \pm 0.02) \\
\end{array}$ & $\begin{array}{c}936.83^{\mathrm{a}} \\
( \pm 11.05) \\
\end{array}$ & $\begin{array}{l}537.48^{a} \\
( \pm 5.13) \\
\end{array}$ & $\begin{array}{c}70.08^{c} \\
( \pm 1.06) \\
\end{array}$ & $\begin{array}{l}116.15^{\mathrm{b}} \\
( \pm 1.06) \\
\end{array}$ & $\begin{array}{c}0.55^{\mathrm{c}} \\
( \pm 0.02) \\
\end{array}$ \\
\hline Sig* & 0.00 & 0.08 & 0.16 & 0.30 & 0.08 & 0.00 & 0.00 & 0.00 \\
\hline
\end{tabular}

MC: Pelet nemi, L: Pelet boyu, D: Pelet çapı, PD: Parça yoğunluğu, BD: Yığın yoğunluğu, PDI: Dayanıklılık direnci, CR: Sıkıştırma direnci.

*Parantez içindeki değerleri ortalamaların standart hatasını ifade etmektedir.

**Aynı sütunda farklı harfleri taşıyan değerler istatistiksel olarak önemli düzeydedir $(\mathrm{p}<0.05)$.

Biyokütleden üretilen peletlerin etkin depolama ve taşıma faaliyetlerinin yürütülebilmesi için yığın yoğunluğu değerinin $\geq$ $600 \mathrm{~kg} \mathrm{~m}^{-3}$ olması gerektiği bildirilmiştir (ENplus 2015). Her üç peletleme neminde üretilen pirina peletlerinin yı̆̆ın yoğunluğu değerleri standartta belirtilen değerin altındadır. Çizelge 2'de belirtildiği gibi, artan nem içeriği hammaddenin bağlayıcılık özelliğini arttırıp daha uzun peletler üretilmesine neden olmuştur. Bu durum sabit hacim içerisinde daha az sayıda peletin bulunabileceğini göstermektedir. $\mathrm{Bu}$ nedenle yüksek nem içeriğinde elde edilen pirina peletlerinin yığın yoğunluğu değerini azalttığı söylenebilir. Yüksek yığın yoğunluğu değeri elde etmek için pirinanın daha düşük nem içeriklerinde peletlenmesi gerektiğini göstermektedir.

Peletleme nem içeriğinin pelet dayanıklılık direncini etkileyen en önemli faktörlerden olduğu bildirilmiştir (Arzola ve ark. 2014). Çalışmada, peletleme nem içeriğinin artışı pelet dayanıklılık direncini arttırmış olup \%13-14, \%17-18 ve \%2021 peletleme nemlerinde dayanıklılık direncini sirasiyla $\% 60.63$, \%64.83 ve \%70.08 olarak hesaplanmıştır (Şekil 5). Standartlara göre pelet dayanıklılık direnci A1 kalite sınıfı için $\% 98$ veya daha fazla, A2 ve B kalite sınıfi için \%97.5 veya daha fazla olması gerektiği bildirilmiştir (ENplus 2015). Zawiślak ve ark. (2020), çeşitli orman ürünleri ve tarımsal artıkların \%8-15 nem aralığında peletlenmesi sonucu dayanıklılık dirençlerin \%90-95 düzeyinde değiştiğini bildirmiştir. Abedi ve ark. (2018)'nın \%6-16 nem içeriği aralığında peletlediği odun talaşının dayanıklılık dirençleri \%57-61 aralığındadır.
Çalışmada üretilen pirina peletleri $\% 60-70$ aralığındaki dayanıklılık direnci değerleriyle standart değerlerin oldukça altında kalmaktadır.

Gerilme direnci peletlerin ezilme ve basinca maruz kalarak kırılma dirençlerini ifade etmektedir. Araştırmada yapılan sıkıştırma direnci testlerine göre, pelet nem içeriğinin artışının peletlerin sıkıştırma direnci değerlerini azalttığı belirlemiştir. Testlerde elde edilen peletlere ait görüntüler Şekil 6'da verilmiştir.

Sıkıştırma direnci testi sonrasında tüm peletler ufalanarak dağılmıştır. Şekil 6 incelendiğinde pirina içerisinde bulunan zeytin çekirdeği parçalarının hammadde bağlayıcılığını ve pelet formunun korunmasını olumsuz yönde etkilediği anlaşılmaktadır. Peletlerin içerisinde bulunan zeytin çekirdeği parçacıkları peletlerin sıkışı ve homojen bir yapı yerine boşluklu ve dayanıksız bir yapıya sahip olmasına neden olmuştur. Abedi ve ark. (2018), farklı büyüklük ve şekillerdeki boşluklu yapının pelet dayanıklılığı ve sıkıştırma dirençlerinde düşüşe sebep olduğunu bildirmiştir. Yapılan çalışmalarda peletlerin kırılmadan önceki maksimum kuvvetleri odun peletlerinde $500 \mathrm{~N}$ (Stelte ve ark. 2013) ve $477 \mathrm{~N}$ (Manouchehrinejad ve Mani 2018), atık çamuru ve odun talaşı karışımı peletlerinde 2.87-4.18 Mpa (Jiang ve ark. 2016) olarak bildirilmiştir. Ruiz Celma ve ark. (2012) ideal peleteme nemine yakınlaştıkça pelet sertliğinin arttığını, en yüksek sertlik değerinin $\% 9$ peletleme neminde $80 \mathrm{~N}$ olarak hesaplandığını bildirmiştir. Çalışmada, yük altında kırılmaya karşı en dayanıklı 


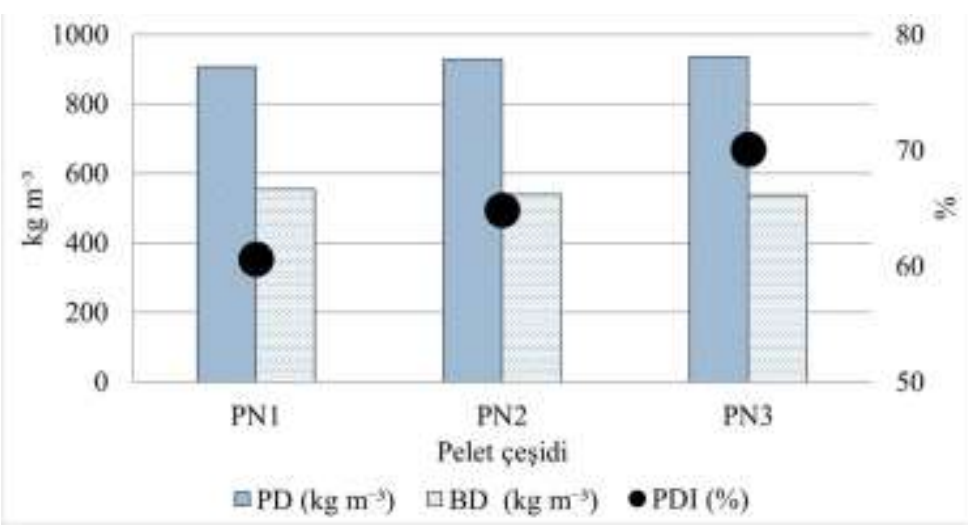

Şekil 5. Pelet nem içeriğinin parça yoğunluğu (PD), yığın yoğunluğu (BD) ve dayanıklılık direnci (PDI) üzerine etkisi.

Figure 5. The effect of pellet moisture content on particle density (PD), bulk density (BD) and pellet durability (PDI) index.

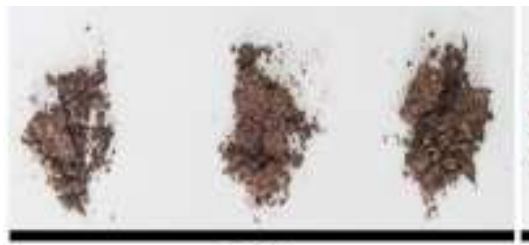

PN1

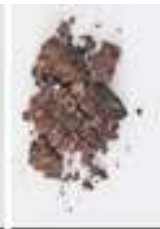

PN2

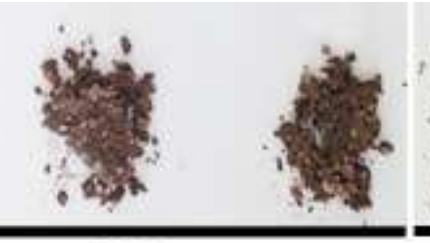

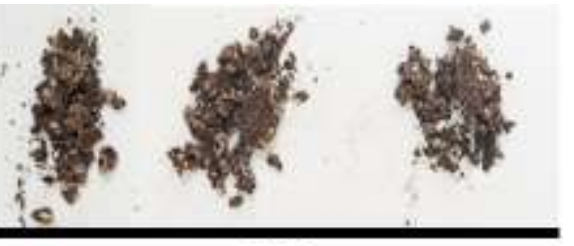

PN3

Şekil 6. Sıkıştırma direnci testi sonrasında peletlerin görünümü.

Figure 6. The appearance of pellets after compression resistance test.

peletler \%20-21 peletleme neminde üretilen PN3 peletleridir. PN3 peletlerinin gerilme dirençleri $0.55 \mathrm{Mpa}$ ile literatürdeki değerlerin oldukça altında hesaplanmıştır. Literatürdeki pelet sertlik testlerinde elde edilen maksimum kırılma kuvveti peletlerin genellikle kırılma ve çatlamaları anında elde edilmektedir. Çalışmada, zeytin çekirdeği parçalarının peletlerde zayıf fiziksel yapı oluşturması, sıkıştırma kuvvetine maruz kalması durumunda dağılmasına ve ufalanmasına sebep olmuştur.

\section{Sonuç}

Çalışmada zeytinyăğ üretimi sırasında ortaya çıkan $5 \mathrm{~mm}$ elek delik çapında öğütülmüş pirina, ek bir öğütme işlemine tabi tutulmadan üç farklı nem içeriğinde peletlenmiş̧tir. Nem içeriğinin artışı hammaddenin bağlayıcıllığını arttırsa da pirina içerisinde bulunan zeytin çekirdeği parçacıkları peletlerin homojen ve dayanıklı bir yapıda olmasını engellemiştir. Elde edilen peletlerde zeytin çekirdeği parçacıkları pelet yüzeyinde gözle görünür biçimdedir ve dayanıklılık direnci ile sıkıştırma direnci testlerinde zeytin çekirdeği parçacıklarının peletlerin ufalanmasına önemli düzeyde etki ettiği anlaşılmıştır. Peletleme neminin artışı pelet üretim kapasitesi, pelet üretiminde harcanan elektrik enerjisi ve peletlerinin fiziksel özelliklerini olumlu yönde etkilemiştir. Buna rağmen pelet fiziksel özellikleri Avrupa Pelet Konseyi'nin belirlediği "ENplus Handbook, Part 3 - Pellet Quality Requirements" pelet yakitı standartlarında yer alan değerleri karşılamamaktadır. Pirinanın etkin bir şekilde peletlenebilmesi ve fiziksel olarak kaliteli peletler üretilebilmesine yönelik araştırmaların yapılması önerilir. Bunun için parçacık boyut dağılımının $1 \mathrm{~mm}$ 'den küçük fraksiyonlarda dağılım göstermesi önemlidir. Bu kapsamda ögütme işlemlerinin $5 \mathrm{~mm}$ 'den küçük elek delik çaplarında yapılmasının gerekli olduğu ortaya çıkmaktadır.

\section{Kaynaklar}

Abedi A, Cheng H, Dalai AK (2018) Effects of natural additives on the properties of sawdust fuel pellets. Energy and Fuels 32: 1863-1873.

Agar DA, Rudolfsson M, Kalén G, Campargue M, Da Silva Perez D, Larsson SH (2018) A systematic study of ring-die pellet production from forest and agricultural biomass. Fuel Processing Technology 180: 47-55.

Akdeniz RC, Shishvan SH (2015) The requirement for new biomass pelletizing test device. Agricultural Engineering 2: 25-34.

Al-Widyan MI, Al-Jalil HF, Abu-Zreig MM, Abu-Hamdeh NH (2002) Physical durability and stability of olive cake briquettes. Canadian Biosystems Engineering / Le Genie des biosystems au Canada 44: 41-45.

Arzola N, Gómez A, Rincón S (2012) The effects of moisture content, particle size and binding agent content on oil palm shell pellet quality parameters. Ingenieria e Investigacion 32: 24-29.

Arzola NA, Gómez A, Rincón S (2014) Experimental study of the mechanical and thermal behavior of pellets produced from oil palm biomass blends. Global Nest Journal 16: 179187.

ASAE (2001) S269.4: In cubes, pellets, and crumblesdefinitions and methods for determining density, durability, and moisture content. St. Joseph, MI: American Society of Agricultural and Biological Engineers.

ASAE S319.3 (2003) Methods for determining and expressing fineness of feed materials by sieving. 2008:S319.2. St. Joseph, MI: American Society of Agricultural and Biological Engineers. 
ASTM E871-82 (2019) Standard test method for moisture analysis of particulate wood fuels. American Society for Testing and Materials, West Conshohocken, PA (United States).

Bilgin S, Yılmaz H, Koçer A, Acar M, Dok M (2014) Ayçiçeği saplarının konik helezon tip briket makinesinde briketlenmesi Briquetting of sunflower stalks in conical screw type briquette machine. Akdeniz Üniversitesi Ziraat Fakültesi Dergisi 27: 91-97.

Bilgin S, Karayel D, Y1lmaz H (2015a) Palmiye Budama Artıklarının Briketlenmesi. 29. Tarımsal Mekanizasyon ve Enerji Kongresi, Diyarbakır, s. 480-486.

Bilgin S, Yılmaz H, Koçer A, Acar M, Dok M (2015b) Fındık Zurufunun Peletlenmesi ve Pelet Fiziksel Özelliklerinin Belirlenmesi. Tarım Makianaları Bilim Dergisi 11: 265-273.

Calderón C, Colla M, Jossart JM, Hemeleers N, Cancian G, Aveni N, Caferri C (2019) BioEnergy Europe Statiscital Report. Place du Champ de Mars 2A 1050 Brussels.

Carroll JP, Finnan J (2012) Physical and chemical properties of pellets from energy crops and cereal straws. Biosystems Engineering 112: 151-159.

Cheng J, Zhou F, Si T, Zhou J, Cen K (2018) Mechanical strength and combustion properties of biomass pellets prepared with coal tar residue as a binder. Fuel Processing Technology 179: 229-237.

Coşkun MB, Yalçin I, Özarslan C (2006) Physical properties of sweet corn seed (Zea mays saccharata Sturt.). Journal of Food Engineering 74: 523-528.

EN 15103 (2009) Solid biofuels - Determination of bulk density. CEN/TS. London, EN: CEN.

EN 15210-1 (2009) Solid biofuels - Determination of mechanical durability of pellets and briquettes - Part 1: Pellets. CEN/TS. London, EN: CEN.

ENplus (2015) Pellet Quality Requirements. Place du Champ de Mars 21050 Brussels, Belgium.

Filbakk T, Jirjis R, Nurmi J, Høibø O (2011) The effect of bark content on quality parameters of Scots pine (Pinus sylvestris L.) pellets. Biomass and Bioenergy 35: 3342-3349.

Garcia-Maraver A (2015) Factors affecting the quality of pellets made from residual biomass of olive trees. Fuel Processing Technology 129: 1-7.

González WA, López D, Pérez JF (2020) Biofuel quality analysis of fallen leaf pellets: Effect of moisture and glycerol contents as binders. Renewable Energy 147: 11391150.

Hocaoglu S, Baştürk İ, Haksevenler BH, Aydöner C (2017) Türkiye'deki Zeytinyağı İşletmelerinin Üretim Süreçleri ve Kapasite Kullanımları Açısından Değerlendirilmesi. Turkish Journal of Agriculture - Food Science and Technology 5: 724.

Huang Y, Finell M, Larsson S, Wang X, Zhang J, Wei R, Liu L (2017) Biofuel pellets made at low moisture content Influence of water in the binding mechanism of densified biomass. Biomass and Bioenergy 98: 8-14.

Jiang L, Yuan X, Xiao Z, Liang J, Li H, Cao L, Wang H, Chen X, Zeng G (2016) A comparative study of biomass pellet and biomass-sludge mixed pellet: Energy input and pellet properties. Energy Conversion and Management 126: 509515.

Kirsten C, Lenz V, Schröder HW, Repke JU (2016) Hay pellets - The influence of particle size reduction on their physicalmechanical quality and energy demand during production. Fuel Processing Technology 148: 163-174.

Korkut S, Mart O, Kuyruk E, Teknik K, Analizi E (2016) Çanakkale ilinde zeytin üretimi artık potansiyelinin belirlenmesi ve değerlendirme olanaklarının araştırılması. Tarım Makinaları Bilimi Dergisi 12: 103-111.

Manouchehrinejad M, Mani S (2018) Torrefaction after pelletization (TAP): Analysis of torrefied pellet quality and co-products. Biomass and Bioenergy 118: 93-104.

Mostafa ME, Hu S, Wang Y, Su S, Hu X, Elsayed SA, Xiang J (2019) The significance of pelletization operating conditions: An analysis of physical and mechanical characteristics as well as energy consumption of biomass pellets. Renewable and Sustainable Energy Reviews 105: 332-348.

Ruiz Celma A, Cuadros F, López-Rodríguez F (2012) Characterization of pellets from industrial tomato residues. Food and Bioproducts Processing 90: 700-706.

Serrano C, Monedero E, Lapuerta M, Portero H (2011) Effect of moisture content, particle size and pine addition on quality parameters of barley straw pellets. Fuel Processing Technology 92: 699-706.

Stelte W, Nielsen NPK, Hansen HO, Dahl J, Shang L, Sanadi AR (2013) Reprint of: Pelletizing properties of torrefied wheat straw. Biomass and Bioenergy 53: 105-112.

Talero Rojas GF, Rincón Prat SL, Gonzalez Hassig A (2016) Use of Colombian oil palm wastes for pellets production: reduction of the process energy consumption by modifying moisture content. WasteEng - 6th International Conference on Engineering for Waste and Biomass Valorisation, Albi, France.

TÜİK (2020) Türkiye İstatistik Kurumu, Bitkisel Üretim İstatistikleri.

https://biruni.tuik.gov.tr/medas $/$ kn $=92 \&$ locale $=\operatorname{tr}$ Erişim 5 Ocak 2021.

Yıldırım R, Tunalığlu R (2016) Aydın'da Karasu Sorunu ve Zeytinyağı İşletmelerinin Çözüme Yönelik Tercihlerinin İncelenmesi. Adnan Menderes Üniversitesi Ziraat Fakültesi Dergisi 13: 39-39.

Yılmaz H, Topakcı M, Karayel D, Çanakcı M (2020) Comparison of the physical properties of cotton and sesame stalk pellets produced at different moisture contents and combustion of the finest pellets. Energy Sources, Part A: Recovery, Utilization, and Environmental Effects. doi: 10.1080/15567036.2020.1850931.

Zawiślak K, Sobczak P, Kraszkiewicz A, Niedziółka I, Parafiniuk S, Kuna-Broniowska I, Tanaś W, ŻukiewiczSobczak W, Obidziński S (2020) The use of lignocellulosic waste in the production of pellets for energy purposes. Renewable Energy 145: 997-1003.

Zvicevičius E, Raila A, Čiplienė A, Černiauskienė Z̆, Kadžiulienė Ž, Tilvikienė V (2018) Effects of moisture and pressure on densification process of raw material from Artemisia dubia Wall. Renewable Energy 119: 185-192. 